\title{
Comparative study for identification of Candida albicans with germ tube test in human serum and plasma
}

\author{
Jeel Moya-Salazar ${ }^{1,2 *}$ and Roberto Rojas ${ }^{3}$ \\ ${ }^{1}$ Department of Pathology, Hospital Nacional Docente Madre Nino San Bartolome, Lima, Peru \\ ${ }^{2}$ Faculties of Health Science and Medicine, Universidad Privada San Juan Bautista, Ica, Peru \\ ${ }^{3}$ Mycology area, Department of Microbiology, Instituto Nacional de Salud del Nino, Lima, Peru
}

\begin{abstract}
The aim of the study was to compare the technique of germ tube in human serum and plasma for the identification of Candida albicans. A cross-sectional prospective study was conducted at La Fe Clinic and the institute "Instituto Nacional de Salud del Niño". Prior informed consent, we obtained plasma samples (voluntary donation) and serum (vein removal) of an apparently healthy donor, without consumption of antifungals, respecting the norms of institutions, quality standards and the inclusion criteria. The samples were stored in cryovials to $\leq 20^{\circ} \mathrm{C}$ until processing; germ tube technique was performed under a conventional method. C. albicans ATCC 14053 was used as a control. A total of 150 tests germ tube technique in plasma and 150 trials in human serum were included for the identification of C. albicans. The sensitivity, spececifity, positive predictive value, and negative predictive value were $100 \%, 99.3 \%, 99.3 \%, 100 \%$, respectively $(\kappa=.99$, CI $95 \%$ : range: 96-1.01). This study allowed us to demonstrate that the technique of germ tube in human plasma is comparable with the technique of germ tube in human serum for the identification of $C$. albicans showing high performance and diagnostic agreement.
\end{abstract}

\section{Introduction}

The progressive increase in incidence of fungal infection over the last three decades is of great importance for communities worldwide and it has as its principal agent the genus Candida, mainly Candida albicans (C. albicans), amply isolated species and prevalent in clinical samples. C. albicans produces mucocutaneous infections, as an opportunist pathogen in oral candidiasis and vulvovaginitis, and exceptionally causes systemic invasive candidemia, principally in critical and immunocompromised patients with AIDS, autoimmune diseases, and transplant recipients [1-4]. The invasive sepsis causes high morbidity and mortality, high hospitalization costs and stays which represent almost a third of nosocomial infections in ICU $[5,6]$. The invasive mycosis is considerate the second most frequently nosocomial infection in Peru, and the fourth in the United States, hence, must perform precise and rapid mycology diagnosis and, that allow corroborating the clinical diagnosis and the establishment of an adequate antifungal treatment.

The assays for phenotypical identification and differentiation of Candida species are automatized, commercial and conventional methods. The first methods are miniaturized biochemical assays of fermentation and carbohydrates assimilation. The commercial methods, such as CHROMAgar, offer a rapid identification, diagnosis confection and recognition of organism mixtures with similar characteristics, but these presents' high costs, disabling its routine use in clinical laboratory, orienting the cost-benefit as a limitation. The yeast development on Sabouraud Dextrose Agar 2\% (gold standard), the zymogram-auxogram and tube germ test are classically used methods. Although these tests present critical points, they are the most used altogether.

From the first research of Reynold and Braude [7], Livingood and Johnson [8], Taschdjian C, et al. [9], and Mackenzie [10] to those made by Kaminsky and Quinlan [11], Berardinelli and Opheim [12], and Hilmioglu et al. [13], the germ tube test is widely considered the better method for the identification of Candida. The germ tube is most economical, rapid, easy and used test for discriminating C. albicans and C. dubliniensis from other species, up to a $98 \%$ of sensitivity [1214]. Nevertheless, this test form part of the three screening tests for differentiation of C. albicans to other species.

This test is realized in a diverse range of media, such as water agar with $1 \%$ milk, BHI, commercial media (broth SST, TSA-BAP, BHI, YEPD free-serum, among others), human serum (fresh, inactivated or frozen) being the most appropriate and feasible for filamentation $[10,11,15]$. Nowadays some modifications of the germ tube test have been developed, being most of the times low-cost-benefit and weakly applicable in screenings at health-care centers, principally in the middle-and-low-income countries.

The use of human plasma as an alternative is a possible additional modality of the test. Most health centers can obtain human plasma, for example, from aliquots of the separation of blood components in blood banking services. Likewise, plasma can be derived from hematology or biochemical areas in medical laboratories. In developing countries, with limitations in health services and prevalent diseases, the mycological diagnosis of Candidiasis requires a high efficiency, high sensibility, and relatively low costs, because new applications and/or modifications of diagnostic methods are required.

*Correspondence to: Jeel Moya-Salazar, Pathology Department, Hospital Nacional Docente Madre Nino San Bartolome, Lima, Peru, Tel: 511-986014954, E-mail: jeel.moya@upsjb.edu.pe

Key words: candida albicans, germ tube test, human serum, plasma

Received: November 09, 2018; Accepted: November 27, 2018; Published: November 30, 2018 
We aimed to compare the technique of germ tube in human plasma and serum for the identification of Candida albicans.

\section{Materials and methods}

\section{Clinical characteristics and donation of plasma and serum}

A non-experimental, cross-sectional study was designed and developed at Instituto Nacional de Salud del Niño (INSN) and the Primary-health Center $\mathrm{La} \mathrm{Fe}$ Clinic both in Lima, Peru. The study had the approval of the Committee of Ethics and Research from the Research Support Department of the institution. The sample size was calculated using EPIDAT v.4.1 (Xunta de Galicia, Spain) considering a sensitivity of 0.95 , heterogeneity of $50 \%$ and an accuracy of 0.04 obtaining a minimum sample size of 120 assays of the germ tube.

Having an informed consent, the samples of an asymptomatic and apparently healthy, donors in the phlebotomy and hematology area in La Fe Clinic, following the next exclusion criteria: a) Serum sampling: blood sample must have a minimum volume of $5 \mathrm{ml}$; lipemic, hemolyzed or evidently contaminated samples; samples were processed for two hours and refrigerated or stored at $\geq 4^{\circ} \mathrm{C}$. b) Plasma sampling: incomplete blood donation or with complications, and no stored fresh plasma or stored at $\geq 70^{\circ} \mathrm{C}$.

The serum sampling was realized with $\mathrm{BD}$-Vacutainer system (Franklin Lakes, New Jersey), following the CLSI H26-A3 y H03-A6 guidelines [16,17]. Each sampling was obtained around in seven tubes, and an additional tube with EDTA or heparin was included for CBC (Complete blood count) and biochemical parameters, as glucose, total proteins, cholesterol, etc. (Figure S1 - supplementary appendix) $[10,18]$. The plasma sampling was performed in the blood banking service of Hospital Nacional Docente Madre Niño San Bartolomé, to
Lima, Perú, which met the requirements of the manual of technical competence and normalized proceedings referred to the institution [19]. Aliquots derived from fresh plasma were fractionated and stored in $2 \mathrm{ml}$ cryovials (Samplix, Laboratorio Muestreo y Análisis, Peru) at $\leq 70^{\circ} \mathrm{C}$ (Figure 1) [20].

\section{Pre-analytical phase}

During the second trimester of 2015, eight strains of C. albicans and C. non-albicans (C. glabrata) were selected and collected from paediatric (children) patients and identified with Vitek 2 Compact (BioMérieux, Marcy-l'Étoile, France) in the microbiological service of INSN. We used C. albicans ATCC 14053 (American Type Culture Collection, Manassas, US) as a performance control in the germ tube test. The cultures were stored in the mycology library to INSN, they were reactivated and isolated in sabouraud dextrose agar (Merck, Darmstadt, Germany) for germ tube assessments, where they were incubated at $36 \pm 1^{\circ} \mathrm{C}$ for 18 to 24 hours [20].

\section{Analytic phase}

The culture of C. albicans strains and ATCC (positive control) was performed in the INSN. A colony was lightly touched with a straight wire and then inoculated in the test tubes containing human plasma and serum. The test tubes were incubated for 2 hours at $37^{\circ} \mathrm{C}$. For reading the test two drops of the aliquot from each test cryovial (human plasma and serum) was withdraw whit a loop, placed on a slide (before submerged in alcohol to avoid fungal growth) and evaluated under a magnification of 40x and 100x for the presence/absence of germ tube.

We considered as a real and positive germ tube structure the elongated daughter cells originated from the round mother cell without any constriction at their origin, and the constriction of the hyphae at

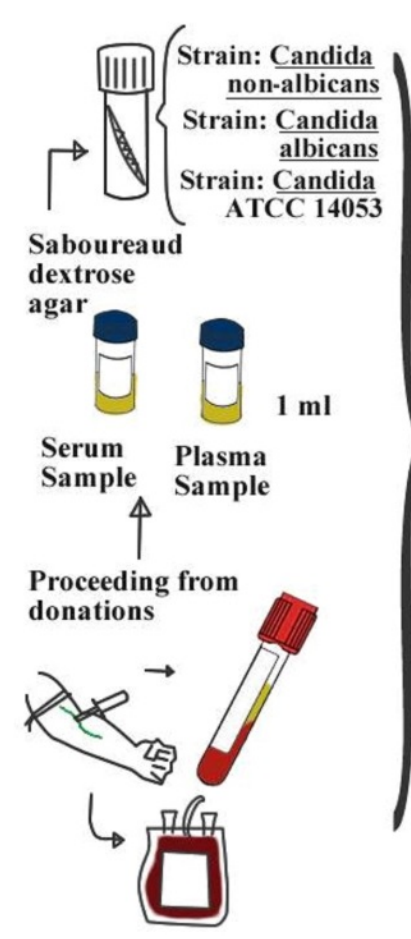

Preanalitic Phase

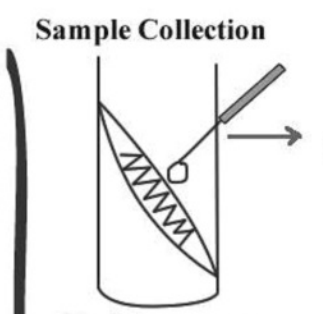

2 to 3 loop passes

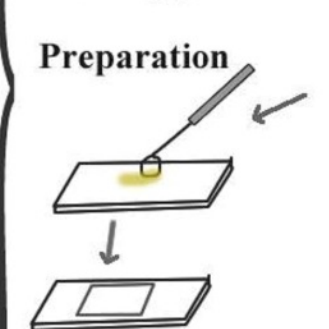

$\downarrow$

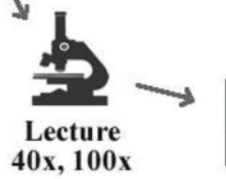

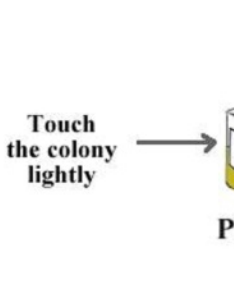

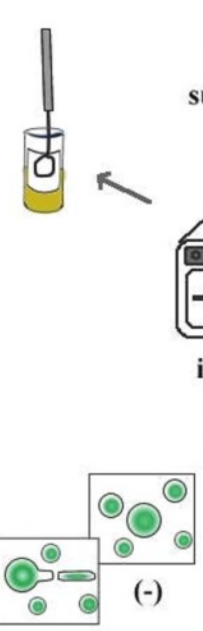

(+)
Interpretation

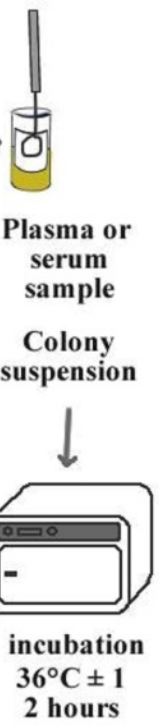

2 hours

Analitic Phase

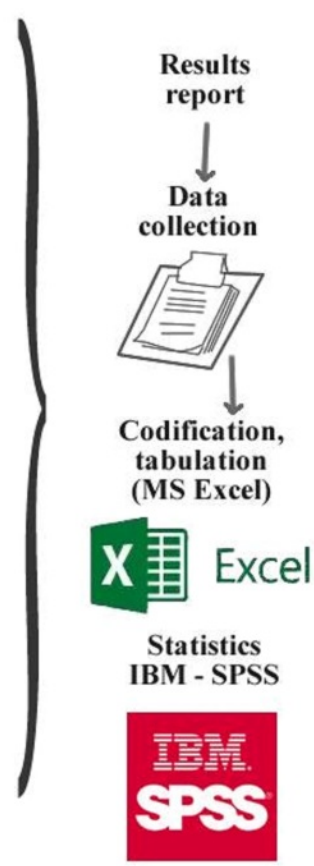

Postanalitic Phase

Figure 1. Flowchart of blood extraction, pre-processing and processing germ tube test in human plasma and serum (colour online only) 
the round mother cell was referred to as pseudo hyphae or sprout of itself $[7,10,21]$. The germ tube has half the width and three to four times the length of a yeast cell. A minimum of seven and twelve fields from the germ tubes was observed respectively as a criterion for germ tube test positivity and negatively.

\section{Data analysis}

Statistical analysis was performed with IBM SPSS v20 (Armonk, USA) for Windows. The diagnosis test was used for comparing the sensitivity of germ tube test in human plasma and serum, considering as a reference standard the germ tube test in human serum. The overall Cohen's Kappa ( $\kappa$ ) inter-test was used and Coeficiente Interval of 95\% was considered statistically significant.

\section{Results}

We included 300 assays (150 for each type of media) that are shown in Table 1, where all false positives are also described. We performed 250 assays with $C$. albicans and 50 assays with C. non-albicans $(C$. glabrata), all the assays were validated with simultaneous processing of C. albicans ATCC 14053.

Table 2 show the diagnostic test, where all positive germ tube tests in human serum also presented filamentation in human plasma. The yield diagnosis of the test in human serum was $83.5 \%$ (150 positive tests) statistically comparable with the values for human plasma $83 \%$ (149 positive assays) $(p=0.120)$. Neither method presented false positive results, $\kappa$ test indicated an excellent agreement between germ tube in plasma and serum ( $\kappa=0.99$, IC $95 \%: 0.96$ to 1.01 ) (Table 1,2 ).

\section{Discussion}

In this study, we scrutinized the germ tube test in human plasma compared with human serum as an important tool for the identification of Candida species, principally C. albicans, showed an excellent agreement and yield diagnosis. Also, iterate its possible cost-benefit aspect.

The rapid identifications of C. albicans are crucial and important in the clinical laboratory because it represents an independent risk factor for invasive candidiasis, it is the most important cause of mortality in critical patients and it is a significant problem of Global Public Health $[5,15,22]$. Numerous scientific evidences suggest that the early

Table 1. Shows an agreement between human plasma and human serum $(n=300)$

\begin{tabular}{|c|c|c|c|}
\hline SGT & \multicolumn{3}{|c|}{ PGT } \\
\hline & Positive & Negative & Total \\
\hline Positive & 149 & 1 & 150 \\
\hline Negative & 0 & 150 & 300 \\
\hline Negative & 149 & 151 & CI 95\% \\
\hline \multirow{2}{*}{ Total } & 0.99 & \multicolumn{2}{|c|}{0.96 a 1.01} \\
\hline
\end{tabular}

SGT: Serum Germ tube Test; PGT: Plasma Germ tube Test

Table 2. Shows a diagnostic test for germ tube in human plasma

\begin{tabular}{|l|c|c|}
\hline Components & & CI 95\% \\
\hline Sensitivity & $99.6 \%$ & $97.8 \%$ a $99 \%$ \\
\hline Specificity & $100 \%$ & $92.9 \%$ a $100 \%$ \\
\hline Valor Predictivo Positivo & $100 \%$ & $98.5 \%$ a $100 \%$ \\
\hline Valor Predictivo Negativo & $98 \%$ & $89.7 \%$ a $99.7 \%$ \\
\hline Proportion of False Positives & $0 \%$ & $0.0 \%$ a $0.71 \%$ \\
\hline Proportion of False Negatives & $0.4 \%$ & $0.1 \%$ a $2.2 \%$ \\
\hline Accuracy & $99.7 \%$ & $98.1 \%$ a $99.9 \%$ \\
\hline
\end{tabular}

implementation of the adequate antifungal therapy is a critical factor in improving the outcome of systemic invasive mycosis occasioned by $C$. albicans, principally in pediatrics and immunocompromised patients [23-25]. It is noteworthy that the opportune management of these cases correspond to a correct and early diagnosis, where the germ tube test constitutes the initial and discriminatory measure for identification of C. albicans. Although it is not the definitive diagnostic test, it is discriminatory for other complementary tests in the correct scheme and it is the most used method in clinical laboratories worldwide $[7,12,14]$.

Otherwise, we show a low rate of false negatives $(0.4 \%)$ and that all negative samples in human serum were negative in human plasma (Table 2). The interpretation of the test as positive is indicated by the production of germ tubes: the growth of filamentous mycelium (morphological transition representing a response to changing environmental conditions). Positive results for germ tube are indicative, preliminary, of the identification of C. albicans and/or $C$. dubliniensis, which can be confirmed and corroborated with different biochemical, molecular and morphological evidence [13,26,27]. The results of this study showed that there exists a correlation in the germ tube test in plasma compared with human sera (Table 1) of strains from cultures identified morphologically and biochemically; results that can be extrapolated to direct determinations from clinical samples, as demonstrated previously in different studies [21,25,28].

The human plasma is an ideal medium for mycotic filamentation of C. albicans which has $100 \%$ of specificity, $99.6 \%$ of sensitivity and $99.7 \%$ of accuracy (Table 2). These results are comparable with other studies for validation of commercial media, where it is repoorted a $~ 96 \%$ of sensitivity and $\sim 98 \%$ of especificity in several media [7,10,26,27,2931]. The agreement level between human plasma and serum was excellent $(\kappa=0.99)$, given that values lower than 0.39 indicate a poor agreement, the values between 0.40 and 0.59 indicate a moderate agreement, and results higher than 0.60 show a substantial and almost perfect agreement. Our results showed an excellent agreement in the determinations of germ tube test for C. albicans [32]. The agreement observed was 1.00 and the agreement that can be expected from random chance was 0.72 (Table 1 ).

Deorukhkar et al. [31] demonstrated that the human plasma is the third best media for the germ tube test in the identification of C. albicans y C. dubliniensis and Berardinelli y Opheim [12] showed an optimal yield with plasma of rabbit. For both, the sobreinoculum generated opposite results that reduced the yield method. Moreover, these methods used trypticase-soy broth (like others who use culture media and rabbit substrates), being these results low cost-benefit and more laborious since for its use as a routine diagnostic method, it should be considered the difficult organization of the sanitary centers and the massive concurrence of patients for diagnosis and treatment.

During the period of the study, there were no studies in Peru that compared human plasma and serum as a media for the development of germ tube in the identification of C. albicans. Our results demostrated a potential utility of human plasma in germ tube testing. Human plasma could be obtained from aliquots derived from the Blood Bank Service, where it secures the media free more or less from pathogens [Human Immunodeficiency Virus (HIV), Human T-lymphotropic virus types-1 and -2 (HTLV), hepatitis B virus (HBV), syphilis, etc.].

In summary, this study allowed us to demonstrate that the technique of germ tube in human plasma compares to the technique of germ tube in human serum for the identification of C. albicans showing 
a high performance and a diagnostic agreement.

\section{Author contributions}

JMS and RRL conceived and designed the experiments. JMS and RRL performed the experiments. JMS analyzed the data and wrote the paper.

\section{Acknowledgments}

We are grateful to Lucy Ibañez Vasquez, Adolfo Ubidia-Incio, Liz Pio-Dávila, Caroline Salvati, and Victor Rojas-Zumaran for their invaluable help. Likewise, we are grateful to all the staff of the $\mathrm{La} \mathrm{Fe}$ Clinic primary health center and the "Instituto Nacional de Salud del Niño" both to Lima, Peru, for all their support of this study.

\section{Conflict of interest}

The authors declare that there are no conflicts of interest.

\section{Funding}

Self-funded for the authors

\section{References}

1. Sobel JD, Muller G, Buckley HR (1984) Critical Role of Germ Tube Formation in the Pathogenesis of Candidal Vaginitis. Infect Immun 44: 576-580. [Crossref]

2. Staab JF, Bradway SD, Fidel PL, Sundstrom P (1999) Adhesive and mammalian transglutaminase substrate properties of Candida albicans Hwp1. Science 283: 15351538. [Crossref]

3. Lau AF, Kabir M, Chen SC, Playford EG, Marriott DJ, et al. (2015) Candida Colonization as a Risk Marker for Invasive Candidiasis in Mixed Medical-Surgical Intensive Care Units: Development and Evaluation of a Simple, Standard Protocol. $J$ Clin Microbiol 53: 1324-1330. [Crossref]

4. Vazquez JA (2010) Invasive fungal infections in the intensive care unit. Semin Respir Crit Care Med 31: 79-86. [Crossref]

5. Edmond MB, Wallace SE, McClish DK, Pfaller MA, Jones RN, et al. (1999) Nosocomial bloodstream infections in United States hospitals: a three years analysis. Clin Infect Dis 29: 239-244. [Crossref]

6. Silva V, Díaz MC, Febré N (2002) Red de Diagnóstico en Micología Médica. Vigilancia de la resistencia de levaduras a antifúngicos. Rev Chil Infect 19: 149-156.

7. Rimek D, Fehse B, Göpel P (2008) Evaluation of Mueller-Hinton-agar as a simple medium for the germ tube production of Candida albicans and Candida dubliniensis. Mycoses 51: 205-208. [Crossref]

8. Hu F, Livingood CS, Johnson P, Pomerat CM (1954) Tissue culture studies on human skin. Arch Derm Syph (Chic.) 70: 1-15.

9. Taschdjian CL, Burchall J, Philip K (1960) Rapid identification of Candida Albicans by filamentation in serum and serum substitutes. Am J Dis Child 99: 212-215. [Crossref]

10. Mackenzie DW (1962) Serum tube identification of Candida albicans. J Clin Pathol 15: 563-565. [Crossref]

11. Kaminsky D, Quinlan JR (1963) A simple inexpensive method for rapid identification of Candida albicans. Am J Clin Pathol 40: 143-145.

12. Berardinelli S, Opheim D (1985) New Germ Tube Induction Medium for the Identification of Candida albicans. J Clin Microbiol 22: 861-862. [Crossref]
13. Hilmioglu S, Macit I, Badak Z (2007) Comparison of 12 liquid media for germ tube production of Candida albicans and C. tropicalis. Mycoses 50: 282-285. [Crossref]

14. Godoy P, Almeida LP, Colombo LA (2001) Identificación de Candida albicans utilizando el medio cromogénico Albicans ID. Rev Iberoam Micol 18: 197-199. [Crossref]

15. Tripathi G, Wiltshire C, Macaskill S, Tournu H, Budge S (2002) Gen4 Coordinates Morphogenetic and Metabolic Responses to Amino Acid Starvation in Candida albicans. EMBO J 21: 5448-5456. [Crossref]

16. Clinical and Laboratory Standards Institute (2007) Procedures for the collection of Diagnosis Blood Specimens by Venipuncture. CLSI document H3-A6 27(26). Clinical and Laboratory Standards Institute, 940 West Valley Road, Suite 1400, Wayne, Pennsylvania 19087-1898 USA.

17. Clinical and Laboratory Standards Institute (2010) Validation, Verification, and Quality Assurance of Automated Hematology Analyzers (Second edition).CLSI document H26-A2, 30(14). Clinical and Laboratory Standards Institute, 940 West Valley Road, Suite 1400, Wayne, Pennsylvania 19087-1898 USA.

18. Vidotto V, Accattatis G, Zhang Q, Campanini G, Aoki S (1996) Glucose influence on germ tube production in Candida albicans. Mycopathologia 133: 143-147. [Crossref]

19. American Association of Blood Banks (2014) Standards for Blood Banks and Transfusion Services. (29th edn), Bethesda (MD): AABB.

20. Murray PR, Baron EJ, Jorgensen JH, Landry ML, Pfaller MA (2007) Manual of Clinical Microbiology. (9th Edn), Washington, DC: ASM press.

21. Kim D, Shin WS, Lee KH, Kim K, Park JY, et al. (2002) Rapid differentiation of Candida albicans from other Candida species using its unique germ tube formation at 39 degrees C. Yeast 19: 957-962. [Crossref]

22. Buffo J, Herman MA, Soll DR (1984) A Characterization of pH-Regulated Dimorphism in Candida albicans. Mycopathologia 85: 21-30. [Crossref]

23. Bykov VL (1991) Velocity of Candida albicans invasion into host tissues. Mycoses 34 293-296. [Crossref]

24. Sardi JC, Scorzoni L, Bernardi T, Fusco-Almeida F, Mendes MJG (2013) Candida species: current epidemiology, pathogenicity, biofilm formation, natural antifungal products and new therapeutic options. J Med Microbiol 62: 10-24. [Crossref]

25. Sheppard CD, Locas MC, Restieri C, Laverdiere M (2008) Utility of the Germ Tube Test for Direct Identification of Candida albicans from Positive Blood Culture Bottles. J Clin Microbiol 46: 3508-3509. [Crossref]

26. Fleming WH, Hopkins JM, Lord GA (1977) New culture medium for presumptive identification of Candida albicans and Cryptococcus neoformans. J Clin Microbiol 5: 236-243. [Crossref]

27. Chan KS, Deepak RN, Tan MG, Tan AL (2011) Abbreviated identification of Candida albicans by the presence of a pseudohyphal fringe ('spiking' appearance) - some caveats. J Med Microbiol 60: 687-688. [Crossref]

28. García H, García S, Copolillo E (2006) Prevalencia de candidiasis vaginal en embarazadas. Identificación de levaduras y sensibilidad a los antifúngicos. Rev Argent Microb 38: 9-12.

29. Potter L, Papasian CJ (1991) Identification of Candida albicans with a commercially prepared germ-tube solution. Clin Lab Sci 4: 121-122. [Crossref]

30. Arora DR, Saini S, Gupta NA (2003) Evaluation of germ tube test in various media Indian J Pathol Microbiol 46: 124-126. [Crossref]

31. Rimek D, Fehse B, Göpel P (2008) Evaluation of different media for germ tube production of Candida albicans and Candida dubliniensis. Mycoses 9: 704-707. [Crossref]

32. Landis JR, Koch GG (1977) The measurement of observer agreement for categorical data. Biometrics 33: 159-174. [Crossref]

Copyright: (C)2018 Moya-Salazar J. This is an open-access article distributed under the terms of the Creative Commons Attribution License, which permits unrestricted use, distribution, and reproduction in any medium, provided the original author and source are credited. 